\title{
LEITURA E PRODUÇÃO DE TEXTOS COMO INSTRUMENTOS DA APRENDIZAGEM EM UM CURSO DE LICENCIATURA EM MATEMÁTICA DO NORTE DO PARANÁ
}

\author{
LECTURE ET PROCTION DES TEXTES COMME INSTRUMENTS \\ D'APPRENTISSAGE DANS UN COURS DE LICENCE EN \\ MATHEMATIQUES AU NORD DU PARANA
}

\author{
David da Silva Pereira ${ }^{1}$ \\ Silvana Dias Cardoso Pereira ${ }^{2}$
}

\begin{abstract}
Resumo: A reforma do currículo de uma Licenciatura em Matemática de uma Instituição de Ensino Pública Federal do Norte do Paraná iniciou um processo de intensificação de esforços que eram realizados no âmbito de um conjunto de disciplinas curriculares de formação geral de profissionais da Educação vinculadas aos Fundamentos Educacionais. Nesses cinco anos, colheu-se alguns elementos que podem ser mobilizados para a reflexão e para o aprimoramento de tais iniciativas que partem da Leitura, como campo de práticas e de investimento, para construir uma expressão dos sentidos apreendidos pelos licenciandos no âmbito da relação professor-aluno, bem como um acompanhamento contínuo do processo de aprimoramento da capacidade de leitura e de expressão escrita. Como resultados pois, algumas reflexões quanto aos modos de enfrentamento dos desafios de aprimoramento da leitura, exercício contínuo da escrita e promoção da reflexão oral acerca da produção em sala de aula.
\end{abstract}

Palavras-chave: Leitura; escrita; aprendizagem.

Resumé: La réforme du programme d'études d'un diplôme de mathématique dans un établissement d'enseignement public féderal dans le nord du Paraná a entamé un processus d'intensification des efforts qui ont été menés dans le cadre d'un ensemble de matières curriculaires pour la formation générale des profissionnels de l'éducation liées aux fondements de l'éducation. Au cours des ces cinq années, certains éléments ont été collectés qui peuvent être mobilisés pour la réflexion et pour l'amelioration de telles initiatives qui partent de la lecture, comme de pratiques et d'investissement, pour construire une expression des sens appréhendés par les étudiants de primier cycle dans le cadre de la relation enseignant-étudiant, ansi qu'un suivi continu du processus d'amélioration des compétences em lecture et en écriture. En conséquence, quelques réflexions sur la façon de relever les défis de l'amélioration de la lecture, de l'exercice continu de l'écriture et de la promotion de la réflexion orale sur la production en classe.

Mots-clé: Lecture; écriture; apprentissage.

\section{Introdução}

A Licenciatura em Matemática como itinerário formativo de profissionais da Educação nacional é uma das três possibilidades de formação de docentes para a Educação Básica. No Campus em questão, de uma Universidade Federal do Norte do Paraná, região conhecida como Norte Pioneiro, esse processo formativo teve início no $2^{\circ}$ Semestre de 2011, por meio da formação da primeira turma selecionado por meio do Sistema Unificado (SISU).

\footnotetext{
${ }^{1}$ Magistério Superior Público Federal.

${ }^{2} \mathrm{FE}$ - Unicamp.
} 
Iniciado em fevereiro de 2013, foi constituído paulatinamente um esforço sistemático de inclusão da leitura, da escrita e do diálogo como instrumentos fundamentais das ações pedagógicas de um conjunto de disciplinas compreendidas no grupo identificado como Fundamentos da Educação. Trata-se de componentes curriculares que possibilitam o diálogo desses elementos de formação com os campos da Filosofia, da História, da Psicologia, da Didática, da Organização e da Gestão do Trabalho Escolar e das Políticas e Normas Educacionais. Tal processo, contudo, ganhou impulso com a alteração curricular preparada e realizada ao longo de 2014 e implementada a partir de 2015.

De modo objetivo, foram inseridas na ementa dessas disciplinas o conjunto de expressões da primeira linha do título a este artigo: "Leitura e Produção de Textos como instrumentos da Aprendizagem". Tal inserção foi fundamental devido a pelo menos três motivos:

- incluir esses elementos fundamentais da formação docente objetivamente em ementas de disciplinas;

- possibilitar por meio de recursos tecnológicos um tempo extraordinário de preparação dos alunos, prévio em relação aos tempos semanais de aulas;

- assegurar uma identidade comum ao conjunto dessas disciplinas que, apesar de concentradas em Fundamentos da Educação, assumiam, por vezes, feições distintas conforme o profissional que tinha a incumbência de as ministrar.

Nesse movimento, a homologação do Parecer n. 02.2015 da Câmara Plena do Conselho Nacional de Educação, em jul. 2015, funcionou como elemento esclarecedor e redirecionador das ações realizadas no âmbito dessa Licenciatura, isolada como modalidade de formação docente inicial nesse Campus, mas que funciona como uma das ofertas dessa Universidade no estado do Paraná.

\section{Um novo currículo para a Matemática}

No ano letivo de 2014, vários encontros do Núcleo Docente Estruturante (NDE) do Curso de Licenciatura em Matemática dessa Universidade Federal se dedicaram a compreensão de como enfrentar dois problemas: 1) a evasão acentuada ao longo do Curso (cerca de $90 \%$ dos ingressantes não concluíam o curso após oito semestres letivos - prazo mínimo estabelecido); II) o altíssimo percentual de ingressantes que não superavam o primeiro período do Curso sem reprovações em disciplinas.

Quanto aos Fundamentos da Educação como campo de conhecimentos e de práticas na forma de aportes para a formação licenciada, havia seis disciplinas ao longo dos oito períodos, assim distribuídas: Filosofia Geral no primeiro período/semestre - com duas aulas semanais de 50 minutos (uma noite); Didática Geral, e História da Educação no segundo - com duas aulas semanais (uma noite cada); Psicologia da Educação no segundo também - com três aulas semanais, cada; Organização do Trabalho Pedagógico e Gestão Escolar no terceiro - com duas aulas semanais (uma noite) e Políticas Educacionais no sexto - com duas aulas semanais (uma noite). Dessa forma, o total de seis componentes curriculares era concentrado nos três primeiros semestres, além da última ministrada no sexto período, já há um ano da conclusão do Curso de Licenciatura. Além disso, um docente com formação pedagógica e pós-graduação na área era responsável pelo conjunto dos últimos cinco componentes, enquanto um outro professor, licenciado em Filosofia, respondia pela oferta da disciplina no primeiro semestre letivo desse Curso, até então, dissociada do diálogo com a Educação. 
Pois bem, a reflexão do NDE do Curso concluiu por uma distribuição mais efetiva desse conjunto de disciplinas ou de componentes curriculares de formação licenciada ao longo dos oito semestre, contudo, ainda concentrado na primeira parte. Explique-se que a partir do quinto período, os licenciandos começam a cumprir um conjunto de outras disciplinas relacionadas à prática do ensino de Matemática e aos Estágios Curriculares obrigatórios, além de outras disciplinas que primam por objetos relacionados ao ensino de Matemática, entre componentes curriculares obrigatórios e optativos.

A partir de 2015, iniciou-se uma nova apresentação dessa organização curricular que, em primeiro lugar, modificou profundamente a Filosofia Geral ministrada no primeiro período. Essa disciplina foi unida à História da Educação, do segundo, para dar origem aos Fundamentos Filosóficos e Históricos da Educação, agora com três aulas semanais. No segundo período dos oito regulares, foi incluída a nova Fundamentos de Didática em substituição à Didática Geral, com a mesa carga horária de duas aulas semanais (uma noite). No terceiro, foi mantida a Psicologia da Educação, com a mesma denominação e carga horária. No quarto semestre, foram incluídos os Fundamentos de Organização do Trabalho Pedagógico e de Gestão Escolar, com as mesmas duas horas semanais. A disciplina Políticas Educacionais foi antecipada do sexto para o quinto semestre e, agora, denominada de "Fundamentos Políticos e Normativos da Educação", com as duas aulas semanais em uma noite de trabalho.

Em princípio, nota-se que houve a redução quantitativa de aulas desse conjunto de disciplinas, das originais 13 para 12. Contudo, a principal transformação se deu no interior de cada um desses componentes curriculares, por meio do acréscimo da "Leitura e Produção de Textos como instrumentos da aprendizagem" não só na ementa, mas também entre os conteúdos e estratégias de enfrentamento dos temas mencionados nos respectivos Planos de Ensino.

Dessa forma, a ementa vinculou o formador a empregar como metodologia de trabalho privilegiada a leitura, a escrita e o diálogo como instrumentos ou mecanismos de aprendizagem. Em termos práticos, o conjunto de disciplinas foi agora confiado a dois profissionais com formação pedagógica, um que trabalharia com o primeiro, o segundo e o quinto semestres, e outro que o faria com os terceiro e quarto semestres, de forma complementar.

Parece pouco, mas essa reforma curricular alterou profundamente o modo como se trabalha a formação docente nesses componentes em vista de, como o anunciado na Introdução:

- incluir esses elementos fundamentais da formação docente objetivamente em ementas de disciplinas - razão pela qual a leitura e a produção de textos passaram, efetivamente, a ter lugar não apenas no conjunto de procedimentos de cada profissional, mas a funcionar como objetivos claros de cada um desses componentes, quanto ao atingimento de patamares superiores de leitura e de escrita;

- possibilitar por meio de recursos tecnológicos um tempo extraordinário de preparação dos alunos, prévio em relação aos tempos semanais de aulas - os textos que funcionam como instrumento dos encontros são selecionados em cada semestre, com vistas a possibilitar o desencadeamento de um conjunto de ações que tem início já no dia subsequente ao último encontro, por meio de sua disponibilização no Ambiente de Aprendizagem empregado pela Universidade - o MOODLE - e a elaboração de um texto próprio, pelo aluno, a partir dos elementos destacados da interpretação da leitura indicada;

- assegurar uma identidade comum ao conjunto dessas disciplinas que, apesar de concentradas em Fundamentos da Educação, assumiam, por vezes, feições distintas conforme o profissional que tinha a incumbência de as ministrar - não apenas pela reforma dos títulos das disciplinas, passou a se verificar uma clara orientação irradiadora dos Fundamentos da Educação como campo teórico-prático de formação docente, no contato com a Filosofia e a 
História (primeiro semestre), com a Didática (segundo), com a Psicologia (terceiro), com a Organização do Trabalho Pedagógico e a Gestão Escolar - OTPGE) e com as Políticas e Normas que dizem respeito à Educação nacional.

Dessa forma, o processo iniciado já em 2013, por meio da inserção de atividades que demandavam ao licenciando em Matemática o contato com textos, exigiam que se detivesse em um esforço de preparação prévio de leituras e de anotações, ainda pontuais, sobre as problemáticas eleitas pelos autores selecionados, passou a um processo sistemático, periódico e investido de mais tempo e de mais atenção, tanto por formadores quanto por formandos.

Esse processo foi aprimorado semestre a semestre por meio de revisões constantes do rol de textos selecionados, do instrumento elaborado para a produção textual, da dinâmica dos encontros presenciais em sala de aula, mas, também e fundamentalmente, de uma gestão mais aprimorada do tempo de preparação do aluno, com atenção para a disponibilização antecipada dos textos, bem como por uma vinculação crescente dos objetivos da disciplina, como componente curricular, com os instrumentos de avaliação - que passaram a incorporar gradativamente tais atividades - como exercícios importantes de aprimoramento do futuro educador.

Não se trata do ensino da Língua Portuguesa nessas disciplinas, mas de desencadear um processo de preocupação e de investimento na leitura, na possibilidade de promover um aprimoramento do emprego da expressão escrita por meio de atividades que demandem esse desafio. Busca-se oferecer um retorno imediato ao aluno quanto à organização das ideias, a observância da estrutura de uma dissertação e à clareza da argumentação de suas ideias a partir dos elementos que colheu dos textos indicados. Em síntese, espera-se que o aluno expresse uma compreensão acerca da leitura e que possa se posicionar com vistas a: 1) organizar as ideias em um texto próprio; 2) apresentar coerentemente seus argumentos; 3 ) demonstrar uma postura crítica e propositiva, já no texto, mas também na problematização no encontro previsto, assim como a contribuição no diálogo com os colegas a fim de resolverem exercícios de expressão oral e escrita em sala.

Dessa forma, o texto indicado é o material fundamental de trabalho dos licenciandos aliado, agora, à produção realizada previamente em formulário próprio a fim de que, em sala, o diálogo possa ser partilhado com os colegas de turma e com o formador.

\section{A promoção da leitura, da escrita e do diálogo em sala - algumas considerações}

A partir dessa dinâmica, que envolve não apenas a preparação semanal para os encontros - que reúne a postagem do texto e a disponibilização da ficha específica pelo formador, além da leitura e a produção do texto prévia pelo aluno - há todo um conjunto de preocupações com a disposição dos licenciandos em sala, de modo a oportunizar, em momentos precisos, os encontros necessários ao diálogo e ao enfrentamento dos desafios na forma de atividades, mas, principalmente, cooperar para que se disponham às trocas, à exposição de seus argumentos, à escuta do outro e à problematização desses elementos.

Nesse processo, de cerca de cinco anos de atividades sistematizadas e pelo menos dez oportunidades de reflexão acerca desse conjunto de práticas, observa-se alguns elementos da formação discente, sobretudo, provinda da Educação Básica nacional.

Há muita resistência de um lado, e extrema dificuldade de expressão de outro. Não apenas com a leitura técnica, de textos do campo da Educação, mas os discentes manifestam questões relacionadas à dificuldade de concentração, manifestam problemas na identificação de elementos simples de argumentação do autor, além de alguma problemática relacionada à identificação da estrutura dos textos. 
A variação entre artigos científicos e capítulos de livros, por exemplo, demanda aos alunos a verificação da obra completa, quer da revista, quer do próprio livro, com vistas à contextualização da produção do texto. Nesse sentido, tem-se incentivado o uso e às visitas à Biblioteca local - do próprio Campus - relativamente bem atualizada com textos relacionados à ementa das disciplinas. Esse é um processo também inovador, pois frequentar uma biblioteca para alunos provindos do Ensino Médio, normalmente de escolas públicas estaduais, ainda que matriculados no período noturno de uma Universidade Pública, é bastante desafiador. Em primeiro lugar, porque esses licenciandos provém não apenas da localidade, mas da região de instalação da Instituição, razão pela qual invariavelmente chegam à Universidade já com a primeira aula iniciada e deixam a sala antes de concluída a última aula da noite. Apesar de funcionar até às $22 \mathrm{~h}$, a biblioteca não está, exatamente, entre as prioridades dos alunos para o emprego do escasso tempo de intervalo entre a terceira e a quarta aulas do período, em vista da preferência absoluta do restaurante universitário.

Em sala, os textos são recebidos após a realização das atividades complementares realizadas em pequenos grupos e, em geral, são devolvidos aos alunos no encontro seguinte - sempre com anotações. Esse elemento é fundamental, o retorno que se dá ao aluno - individualmente - quer em sala, quer em um tempo especial de atendimento fora do horário de aula e ajustado caso-a-caso em vista da confiança manifestada. Sim. A entrega de um texto pelo aluno é um ato, em primeiro, de coragem. Em segundo lugar, de confiança no profissional que o recebe. Tal confiança deve ser honrada, de modo a que o aluno tenha a possibilidade de dialogar com o formador reservadamente. Em sala, é possível perceber a mobilização dos elementos colhidos na leitura e no esforço de produção textual por meio das manifestações dos discentes, tanto nos pequenos grupos de trabalho, quanto nas plenárias que discutem elementos e problemáticas oferecidas pelo autor, mas também as questões que emergem do diálogo entre alunos e desses com o formador.

Há, em autores contemporâneos, uma preocupação profunda com esse processo de leitura e de produção de textos. É possível encontrar discussões próprias do emprego adequado da língua, da promoção continuada da escrita correta, uso adequado da pontuação e expressão clara e coerente das ideias.

Contudo, há também contribuições de pensadores clássicos contemporâneos, que fizeram uso da leitura e da escrita como meios de expressão de suas ideias e de suas visões de mundo.

Um autor como Michel Foucault, por exemplo, retorna aos gregos da Antiguidade Clássica para tomar, da prática estoica, o uso das epístolas por autores como Sêneca. Em inúmeros textos, a prática epistolar é empregada como meio de uma terapêutica, como forma de expressão do cotidiano e de um relato acerca de si. Não apenas Sêneca, mas também Marco Aurélio - o imperador filósofo - emerge nesses escritos foucaultianos como personagem que fez uso constante de cartas.

É nesse contexto, de reflexão sobre as práticas de si, que o Último Foucault - o filósofo dos Cursos do Collège de France empregou Sêneca, Marco Aurélio e outros para a fim de problematizar as técnicas que compunham uma arte de existência. Nesse processo, Filosofia e Religião estão entrelaçadas como suporte de técnicas de si:

Le Nouveau souci de soi implique une nouvelle expérience de soi. On peur voit quelle formme prend cette nouvelle expérience de soi primière et aux deuxième siècle, oú l'interospection devient de plus em plus fouillée. Un rapport se noue entre l'écriture et la vigilance. On prête attention aux nuances de la vie, aux états d'âme et à la lecture, et l'acte d'écrire intensifie et approfondir l'expérience de soi. Tout un champ d'experiences s'ouvre, que n'existait pas auparavant. (FOUCAULT, 2017, p. 1605) 
Michel Foucault destaca a emergência de um cuidado de si como nova experiência de si consigo. Enfatiza, e isso é extraordinário, a centralidade da escrita de si e de uma vigilância contínua de si por si mesmo em um quadro em que os detalhes do cotidiano, do vivido e do percebido como estados da alma. Nesse processo, a leitura e a escrita funcionam como instrumentos de um conjunto de exercícios espirituais que tinham lugar amplo por meio das correspondências trocadas entre mestre e discípulo, conselheiro e aconselhados, mas também entre amantes. Nesses contextos, as trocas de epístolas entre Sêneca e seus aconselhados, mas também a comunicação intensa entre Marco Aurélio e Frontão, referidas por Foucault como elementos fundamentais de um cuidado de si sobre si.

Na relação professor-aluno, um cuidado inspirado nessa narrativa pode ter lugar no modo como se dá a análise do texto, como as anotações são elaboradas e, principalmente, por meio da forma de devolutiva ao aluno, sempre com vistas ao aprimoramento contínuo de suas possibilidades de expressão.

Em um meio não muito favorável ao trabalho com textos, é importante verificar que a coerência e a sistematização dessas práticas jogam um papel muito importante nessas idas e vindas dos formulários, nas práticas de expressão realizadas em sala de aula e no desenvolvimento de uma capacidade de apresentação das ideias, de disposição para o diálogo, mas, sobretudo, de escuta do outro.

A leitura das cartas nas narrativas de Foucault acerca dos estoicos tinha papel preponderante para uma espécie de diagnóstico do estado da alma e de uma devolutiva capaz de animar o ser, de apresentar-lhe as possibilidades de aprimoramento colhidas dos elementos do cotidiano. De forma semelhante, considera-se que há um trabalho minucioso a ser realizado pelo formador quanto ao material oferecido pelos alunos, trabalho esse que vai além de uma obrigação semanal ou quinzenal de efetuar um lançamento de nota, mas que significa um cuidado, um investimento, um trabalho minucioso e preciso realizado por meio do diálogo com o licenciando, com vistas ao aprimoramento contínuo dessa capacidade de comunicação e de expressão das ideias, por meio do texto escrito e pela palavra verbalizada.

Esse emprego do texto como um canal amplo de diálogo faz com que o encontro da sala de aula não se dê não somente como um momento em meio a tantas outras atividades semanais, mas que tenha um lugar de destaque como uma sessão de trabalho por meio da qual se dispõe os sujeitos para o encontro. Dispor-se para o encontro efetivamente implica em tê-lo preparado, ter investido na sua realização, tanto o formador quanto os formandos. De outra forma, cuida-se de estimular a curiosidade, a motivação e a expectativa do licenciando para um encontro consigo, um encontro com o outro, um encontro que trará inúmeros desafios em seu itinerário formativo, desafio de se abrir para o diálogo a partir do que elaborou, desafio de ouvir o outro e pensar sobre o que preparou para esse encontro, desafio de considerar os elementos que são mobilizados como possibilidades a agregar em sua formação, como estímulos de um aprimoramento vertical e constante.

Mais do que responsabilizar o percurso da Educação Básica pelo que, eventualmente, não ofereceu de elementos de formação, é preciso retomá-lo nessa experiência da Educação Superior para ressignificar o presente como conjunto de possibilidades de uma nova formação, mais consciente, mais autônoma.

É nesse movimento que as críticas de Bourdieu sobre a instituição escola e de seu papel na reprodução da organização social vem à baila, como possibilidade de construção de um contradiscurso, de construção de uma outra sala de aula, prenhe de possibilidades e de diálogos. Em entrevista de Roger Chartier, a obra de Bourdieu foi assim sintetizada:

Pour Bourdieu, l'habitus est produit par l'incorporation dans l'individu depuis la prime enfance et ensuite par des institutions comme l'école d'un 
ordre social; et cette incorporation devient productrice de représentations, de jugements, de classements para lesqueles chaque mot, chaque pratique, chaque gest est engendré. (CHARTIER, 2008, p. 91).

Como se percebe, Chartier destaca no conceito de habitus de Bourdieu, a importância das palavras, das práticas e dos gestos no engendramento da condição de classe, da condição para ocupar um determinado lugar na sociedade, condição essa colocada em questão pelos licenciandos que ousam ocupar outros lugares nessa sociedade.

$\mathrm{O}$ ingresso no Curso Superior no Brasil significa uma passagem fundamental que corresponde a saída da Educação Básica e o ingresso na Educação Superior. Para além desse salto entre níveis educacionais, nos termos do art. 21, I e II da Lei de Diretrizes e Bases da Educação Nacional (LDBEN), trata-se do ingresso em um processo profissionalizador e formador de um docente, alguém que dirigirá o processo de ensino-aprendizagem. Nesse contexto, a tão almejada autonomização do sujeito, negada no Ensino Fundamental e também na Ensino Médio, apresentar-se-á ao licenciando no itinerário formativo de alguém que estará na condução dos meios e dos recursos mobilizados para a aprendizagem de sujeitos.

Essa questão é bastante delicada e chama muito a atenção que, de toda a riqueza e possibilidades do conceito de habitus em Bourdieu, Roger Chartier volte o olhar para os detalhes, para os elementos que serão incorporados ao sujeito ainda no processo deformador de escolarização, elementos esses dos quais os licenciandos precisarão "se libertar" para assumirem, de fato, o lugar que constroem de um docente que promova a apprentissage, que estimule o agir ético e que defenda o direito inalienável de escuta e de fala em sala de aula.

Com Bourdieu, tem-se um aspecto do trabalho pedagógico associado à constituição do conceito de habitus:

Le travail pédagogique comme travail d'inculcation qui doit durer assez pour produire une formation durable, i. e. un habitus comme produit de l'intériorisation des principes d'un arbitraire culturel capable de se perpétuer après la cessation de l'AP et par là de pérpetuer dans le pratiques les principes de l'arbitraire intériorisé. (BOURDIEU, 1970, págs. 46-7).

Dessa forma, o trabalho de sala de aula nesse encontros se destina a desarmar esse mecanismo a fim de que os futuros docentes possam sabotar, cada vez mais, essa engrenagem.

\section{Considerações finais}

Buscou-se pensar a partir da prática (des)formadora possibilidades de mobilizar a leitura, a produção de texto e o diálogo em sala de aula como mecanismos de autonomia dos sujeitos, de escuta e de fala, mas, fundamentalmente, de transformação profunda de si.

O itinerário formativo que os licenciandos portam de alguma forma os conduziu a um processo formativo docente para o retorno à Educação Básica. Esse retorno precisa se dar em outras condições, por meio do enriquecimento do processo licenciado por experiências de valorização da escuta e da fala, de exercícios contínuos de produção e de reelaboração de textos.

Nessa direção, o caso da reforma curricular implementada a partir de 2015 em uma Licenciatura em Matemática de uma Universidade Pública Federal do Norte do Paraná oferece elementos para a reflexão sobre a prática docente, a partir das ações formativas e na direção da promoção do aprimoramento da comunicação por meio da leitura, da escrita e do diálogo. Assim, foi possível pensar com autores como Foucault, Chartier e Bourdieu elementos que marcam o percurso escolar e que se fazem presentes no início da Educação Superior, mesmo 
em uma realidade tão distante e em um outro tempo, mas com o mesmo desafio - fazer desses encontros formativos possibilidades outras de construção de uma docência ativa e compromissada com a formação do outro.

\section{Referências}

BOURDIEU, Pierre; PASSERON, Jean-Claude. La Reproduction: éléments pour une théorie du système d'einseignement. Paris: Les Éditions de Minuit. (Collection “Le Sens Commun”).

CHARTIER, Roger. Le Sociologue et le Historien. Entretien avec Roger Chartier. In: FOURNIER, Maurice (Coord.). Pierre Bourdieu: son oeuvre, son héritage. Paris: Éd. Sciences Humaines, 2008. p. 87-95. (La Petite Bibliothèque de Sciences Humaines).

FOUCAULT, Michel. Les Techiques de Soi. In: FOUCAULT, Michel. Dits et Écrits, II (19751988). Éditions établie sous la direction de Daniel Defert et de François Ewald avec la collaboration de Jacques Lagrange. Paris: Quarto-Gallimard, 2017. ed. rev. p. 1602-32.

\section{Sobre os autores}

David da Silva Pereira: Professor- visitante (Pós-doutorando) do Programa de Pós-Graduação em Educação da Faculdade de Educação da Unicamp entre maio/2018 e maio/2020.

E-mail: davidsp01@yahoo.com.br.

Silvana Dias Cardoso Pereira: Doutoranda em Educação no Programa de Pós-Graduação da Faculdade de Educação da Unicamp junto ao Grupo ALLE/AULA.

E-mail: davidpereira@utfpr.edu.br. 